\title{
CORRELATIONS BETWEEN PRO-SOCIAL STATE DE-INDIVIDUATION AND PRO-INDIVIDUAL TRAIT CREATIVITY AMONG SECONDARY SCHOOL STUDENTS IN ESTONIA
}

\section{SUMMARY}

Introduction. An attempt was made to study possible correlations between pro-individual trait (creativity) and pro-social state (de-individuation), among secondary school students in different schools in Tallinn (Estonia).

Aim of the Study. To show that different aspects of pro-social behaviour can correlate with and affect pro-individual trait, as creative thinking, in secondary school students, i.e. the age of increased emotional vulnerability.

Materials and Methods. In the present study, Torrance Test of Creative Thinking, and deindividuation scale, constructed especially for the current study, was used, the empricial study was carried out in a classroom-environment.

Results. There is weak correlationn between creative thinking and de-individuation state.

Conclusions. Further studies on the subject are needed to identify the nature of correlations between pro-social and pro-individual traits.

Key words: creativity, de-individuation, group behaviour

\section{INTRODUCTION}

The present study is an attempt to link two phenomena, which are perceived very differently: de-individuation and creative thinking. The first one, being one of the oldest psychologically described and studied problems (e.g. Le Bon, 1895/1995), is mainly seen as negative state of human psychology. L. H. Coleman, C. E. Paternite and R. C. Sherman (Coleman, Paternite, Sherman, 1999) descrive de-individuation as a state, in which a person's individual perception is decreased, self-identity is decreased and/or substituted by group identity, person ,forgets” himself in the activity, and perceives himself mainly as a group member, not individual. These aspects affect sense of anonymity, which in turn, predisposes anti-social behaviour. Both classical (e.g. Festinger, Pepitone, Newcombe, 1952; Diener, 1977), and modern (e.g. Reicher, Levine, 1994) deindividuation researchers agree that although there are evidence that de-individuation can foster pro-social and positively perceived behaviour (as de-individuated person's behaviour is highly socially regulated, and therefore the stronger are moral rules and obligations within the group, the more likely the person's behaviour would remain pro-social (e. g. Kugihara, 2001; Johnson, Downing, 1979) - still studies on de-individuation are mainly focused on the possible negative aspects of de-individuated group members, such as higher aggression, conformity, anonymity, and self-identity loss.

The second research object of the present study, creative thinking, is mainly perceived and treated as positive aspect of human behaviour (Guilford, 1965; Lubart, 1994). F. Barron and D. M. Harrington (Barron, Harrington, 1981) define creativity as interpersonal and intrapersonal 
process, which results in high-quality, original and valuable outcomes, both from individual and group point of view. T. M. Amabile (Amabile, 1990), in the creative components model, suggests that intrinsic motivation, creativity-related skills, and field-specific skills/ knowledge are the main predictors of creative thinking. R. J. Sternberg and T. I. Lubart (Sternberg, Lubart, 1996) suggest investment model - creative persons ,buy cheap and sell expensive“. Therefore creativity is viewed as positive, and highly social phenomenon, which can occur also in groups. According to R. Helson (Helson, 1999), the main characteristics of creative person's personality, are: originality, readiness to react to environmental changes, devotion towards one's work (i. e. intrinsic motivation), and opposite personal traits that are successfully combined within person's behavioural patterns (e. g. fantasizing vs high reality perception; introversion vs extraversion; etc).

Idea for combining these psychological phenomena in the current study is the nature and characteristics of the studied group, i.e. secondary school students, and the classroom environment they are working in. De-individuation process occurs in group situations, leading to increased conformity, group-identity, diffusing into group actvities, therefore deminishing person's own initiative and awareness of one's own personality and behaviour. Creativity, on the opposite, is strongly connected with personality, e.g. R. Helson and J. L. Pals (Helson, Pals, 2000) found correlations between creative achievements and intrapsychic and psychosocial factors in one's personality development. Classroom environment in many ways fosters group behaviour, although its' aim is to develop each student's personal characteristics at its best. In group situations creativity is not being expressed with maximum strentgh, because group dynamics and group environment require from their members mainly following the chosen behavioural pattern of the particular group, mainly illustrated by loss of personal identity (Coleman et al., 1999). E. K. Starkweather (Starkweather, 1964; cited in Van Hook, Tegano, 2002) found that freedom of expression is strongly bound with creativity - it is person's freedom and ability to express himself, being independent of conformist boundaries, and it is common to higly creative persons; at the same time, both extremely conformist, and extremely non-conformist behavioural pattern is common to lower creativity levels, as both very conformist and very non-conformist behaviours are actually boundaries that set limitations to personality development (Van Hook, Tegano, 2002).

\section{AIM OF THE STUDY}

To determine possible relations between pro-social state (de-individuation) and proindividual trait (creativity, i.e. creative thinking) - therefore to give answer, if and how much pro-individual trait, such as creative thinking, can be affected by group behavioural factor as deindividuation.

\section{MATERIALS AND METHODS}

Total number of participants in the current study was 307 ( $n=307$, males $n=125$, females $\mathrm{n}=182)$, with average age 17,59 yo $(S D=0,746)$; youngest participant being 16 yo, and the oldest 19 yo. All participants were from 5 differents secondary schools, from Tallinn and surroundings.

As first instrument, The Torrance Test of Creative Thinking, Figural Test (Torrance, 1974; Estonian Adaptation by Heinla, 2002) was used. These tests assess four components of creative thinking: fluency (the ability to recall the acquired knowledge and information, and to bring forth associations); originality (finding novel links, producing novel ideas and solutions; presenting the known ideas in a new way); flexibility (producing ideas on various subjects from different fields and sources; the ability to switch rapidly from one class of objects to another; elaboration (the ability to complement ideas and solutions in order to make them more complicated and complete, 
Torrance, 1968). According to G. A. Davis (Davis, 1989), first 3 components - fluency, originality, and flexibility - characterize creative thinking the most, therefore $4^{\text {th }}$ component, elaboration, was not used in the assessment.

The Torrance Tests of Creative Thinking chosen for this study were adapted to Estonian conditions: a new scale of evaluation for measuring originality of thinking in each subtest was worked out, based on the Estonian children's test results $(n=700)$ and following the frequency of original answers given in the Manual of the Torrance Tests of Creative Thinking (Torrance, 1974). The validity and reliability of the tests in Estonia were checked and test norms for 6 - 18-year-olds were developed (Heinla, 2002).

As the second measurement, special de-individuation questionnaire was designed for this particular study. Using theoretical data on de-individuation (Reicher, Levine, 1994; Coleman et al., 1999; Postmes, 2001), and taking SIDE model as basis (Reicher, 1984), 30 statements were put together as de-individuation scale, which consists of three subscales: Identity subscale, based on Coleman et al (Coleman et. al., 1999) self-awareness and self-identity data; Initiativity subscale, based on Maslach Individuation scale (Maslach, Stapp, Santee, 1985); and Antinormativity subscale, where questions from STAXI and STAXI-2 (State-Trait Anger Expression Inventory, Spielberger, 1988 ; 1999) were used as basis. De-individuation questionnaire was submitted for group of experts (psychologists, teachers) to review and get feedback on validity.

The study was conducted in classrooms, during one academic lesson (45 min), and during that time students completed both tests. Results were anonymous, and after completing the study, universal feedback was given to the participants. Prior to empirical study, every secondary school's staff and responsible teacher were asked for permission. Response rate in the study was $100 \%(n=307)$.

All answers were analised, using factor and regression analysis, with statistics programme SPSS 15.0 for Windows.

\section{RESULTS}

First, factor analysis was done for the de-individuation scale, reducing final amount of statements to 25 , and the following factors: Aggressivity (variability $18 \% ; 8$ statements, e.g. At the moment I feel anger, At the moment I want to shout at somebody); Group behaviour (variability 15\%; 11 statements, e.g. At the moment I don't want to volunteer as group leader, At the moment I don't want to perform to large audience); Group identity (variability 8\%; 6 statements, e.g. At the moment I feel that I belong to the same group as people around me, At the moment I feel that I am exactly the same as others). From these factors, no significant differences between male and female respondents were found $(p<0,05)$ for group behaviour and group identity. However, aggressivity average score was higher among males: male $M=13,2, S D=6,2$; female $M=11,4, S D=4,7 ; t(218,874)=2,674, p<0,05$.

There were no significant differences in correlation with age and school. Correlation between 3 de-individuation components showed that there was statistically significant weak correlation between aggressivity and group behaviour $(r=0,13 ; p<0,05)$.

Creative thinking measurements were given at three parameters: raw average scores (originality, flexibility, fluency); levels of creative thinking components (low, medium, high); and, creative thinking levels - combined on 3 creative thinking components (lower, medium, and higher creative thinking).

As parameters for testing creative thinking components are different, to make levels of creative thinking components, test results were transformed into standart deviation units (SDU), then to common 10-point scale, and according to the results, levels were composed (see Table 1). 
Table 1. Creative thinking components levels, with scores

\begin{tabular}{llcccc}
\hline $\begin{array}{l}\text { Creative Thinking } \\
\text { component }\end{array}$ & $\begin{array}{l}\text { Level } \\
\text { group }\end{array}$ & $\begin{array}{c}\text { Level group min } \\
\text { score, raw points }\end{array}$ & $\begin{array}{c}\text { Level group max } \\
\text { score, raw points }\end{array}$ & $\begin{array}{c}\text { Respondents \% in } \\
\text { the group }\end{array}$ & $\begin{array}{c}\text { Respondents } \\
\text { amount in group, } \mathbf{n}\end{array}$ \\
\hline $\begin{array}{l}\text { Originality of } \\
\text { thoughts }\end{array}$ & Low & 4 & 23 & 23,5 & 72 \\
& Medium & 24 & 39 & 55,0 & 169 \\
& High & 40 & 66 & 21,2 & 65 \\
\hline Fluency of thoughts & Low & 11 & 22 & 20,7 & 63 \\
& Medium & 23 & 34 & 54,8 & 167 \\
& High & 35 & 51 & 24,6 & 75 \\
\hline Flexibility of & Low & 6 & 17 & 25,1 & 77 \\
thoughts & Medium & 18 & 25 & 51,1 & 157 \\
& High & 26 & 35 & 23,8 & 73 \\
\hline
\end{tabular}

Originality of thoughts is the most important component of creative thinking (Torrance, 1974), therefore while making levels of creative thinking, emphasis was on levels of originality among respondents. Based on leves of creative thinking components, creative thinking general categories were composed (see Table 2).

Table 2. Creative thinking general level groups, with combinations of component levels

\begin{tabular}{|c|c|c|c|c|c|c|c|c|}
\hline \multirow{2}{*}{$\begin{array}{l}\text { General levels } \\
\text { of creative } \\
\text { thinking }\end{array}$} & \multicolumn{3}{|c|}{$\begin{array}{c}\text { Creative thinking component level } \\
\text { group }\end{array}$} & \multicolumn{2}{|c|}{ Population } & \multicolumn{3}{|c|}{$\begin{array}{c}\text { Creative thinking components avg } \\
\text { score, raw points }\end{array}$} \\
\hline & Originality & Fluency & Flexibility & Amount, $n$ & $\begin{array}{l}\% \text { of } \\
\text { total }\end{array}$ & Originality & Fluency & Flexibility \\
\hline \multirow[t]{6}{*}{ Lower creativity } & A (low) & A & A & 100 & 32,57 & 21,93 & 20,76 & 16,12 \\
\hline & B (medium) & A & A & & & & & \\
\hline & A & A & B & & & & & \\
\hline & A & B & A & & & & & \\
\hline & B & B & A & & & & & \\
\hline & $\mathrm{B}$ & A & $\mathrm{B}$ & & & & & \\
\hline \multirow{4}{*}{$\begin{array}{l}\text { Medium } \\
\text { creativity }\end{array}$} & A & B & B & 140 & 45,60 & 32,73 & 29,39 & 22,09 \\
\hline & $\mathrm{B}$ & B & B & & & & & \\
\hline & B & C (high) & B & & & & & \\
\hline & $\mathrm{B}$ & $\mathrm{B}$ & $\mathrm{C}$ & & & & & \\
\hline \multirow[t]{5}{*}{ High creativity } & $\mathrm{C}$ & B & B & 67 & 21,82 & 43,93 & 38,94 & 27,54 \\
\hline & $\mathrm{C}$ & $\mathrm{C}$ & $\mathrm{C}$ & & & & & \\
\hline & $\mathrm{C}$ & $\mathrm{C}$ & B & & & & & \\
\hline & $\mathrm{C}$ & B & $\mathrm{C}$ & & & & & \\
\hline & B & $\mathrm{C}$ & $\mathrm{C}$ & & & & & \\
\hline
\end{tabular}

Comparing de-individuation components with creative thinking components raw scores, at the level $p<0,01$ there was statistically significant weak negative correlation between originality of thoughts and group behaviour $(r=-0,23)$, thoughts fluency and group behaviour $(r=-0,23)$, and thoughts flexibility and group behaviour $(r=-0,22)$. Male respondents showed statistically significant weak negative correlation only between group behaviour and thoughts fluency $(r=-0,23 ; p<0,01)$; female respondents showed on the level $p<0,01$ statistically significant weak negative correlation 
between originality of thoughts and group behaviour $(r=-0,29)$, thoughts fluency and group behaviour $(r=-0,20)$, and thoughts flexibility and group behaviour $(r=-0,26)$.

Comparing de-individuation components with creative thinking components levels on the level $p<0,05$ only group behavour had statistically significant correlations with creative thinkg components levels: Post-Hoc average compare with Bonferroni test showed that low originality level average score on group behaviour $(M=28,6, S D=6,3)$ was significantly different from high originality level average score $(M=24,6, S D=6,1) ; F=6,39, p<0,05$. Thoughts fluency Post-Hoc average compare with Bonferroni test showed that high fluency level average score on group behaviour $(M=23,7$, $S D=7,2)$ was significantly lower than low fluency level average score $(M=28,7, S D=6,1)$, and than medium fluency level average score $(M=27,3, S D=6,1) ; F=11,93, p<0,05$. Thoughts flexibility PostHoc average compare with Bonferroni test also showed that high flexibility level average score on group behaviour $(M=23,9, S D=6,7)$ was significantly lower than both low flexibility level average score $(M=27,9, S D=6,2)$, and than medium flexibility level average score $(M=27,5, S D=6,4) ; F=9,69$, $p<0,05$.

De-individuation components differences between creative thinking complex levels were measured, and analysis showed that only group behaviour had statistically significant differences in scores: low creativity level group average score on group behaviour $(M=28,7, S D=6,1)$ was significantly higher than both medium-creativity group level average score $(M=26,6, S D=6,6)$, and highly creative level group average $(M=24,3, S D=6,6) ; F=9,588, p<0,05$.

\section{CONCLUSIONS}

De-individuation as state, and its possible correlation to creative thinking, as one the most important characteristics of creativity expression, was studied for several reasons. First, contemporary authors (e.g. Amabile, 1990) believe that creativity is influenced also by personal traits, as being base for most of human behavioral processes - cognitive decisions, risk taking judgement, intrinsic motivation etc. These characteristics are also related to de-individuation, therefore it is important to know if creative persons are easier or harder to be affected by group behaviour factor, or deindividuation. Second, both de-individuation and creativity have human behaviour as an outcome and both de-individuation and creativity have the same behavioural poles (conformity-nonconformity, intrinsic vs extrinsic motivation, personal vs group identity). Therefore there might be much more common between de-individuation, which regularly is seen as negative, and creativity, which is usually regarded as positive trait.

The current study aimed to show that de-individuation and creative thinking are negatively correlated: the more creative person is, the less he/she tends to get into de-individualized situations, or in other words, the more creative the person is, the less he/she can be affected by pro-social states, by others' behaviour and group demands. This aim of the study was partially proven, as of three deindividuation components - aggressivity, group behaviour and group identity - only group behaviour had significant (although weak) correlation with creative thinking.

Group behaviour is one of major de-individuation components (Postmes, Spears, 1998; Reicher, 1987) - it gives possibility to judge the group, and measure its' members stait of mind, it is the process from de-individuation point. On the other hand, behaviour can be seen as result, and this is important for measuring creative thinking - therefore group behaviour, being as major behavioural component in one phenomenon, also plays part as possible outcome in the other. The more creative a person is, the less group behaviour he/she shows - and the less dependent he/she is of the group. This is the main finding of the study, although further explorations need to be done. 
Other de-individuation parameters, aggressivity and group identity, were not significantly correlated with creative thinking in this study. Reasons for that might be weak connection between de-individuation subscales, questionnable validity of the construct (which was designed especially for this study, therefore it is difficult to compare it with other similar studies), social aspect (while answering on aggression-related questions). Also aggression is often subconscious process of deindividuation (Coleman et al., 1999), therefore participants of the study might have been confused with the subscale.

Nevertheless creative thinking and de-individuation might have more connections that it was showed in the present study, e.g. group behaviour stronger negative correlation with creative thinking, or group identity connection to creative thinking components.

The present study answered only partially the question whether de-individuation and creativity are correlated. Further studies are required to explore the subject more profoundly, and to get more scientific proof for that claim. However, the first attempt was made to prove that creativity and behavioural processes have much more in common, and the correlations between them are much more stronger than we suppose: although negatively correlated in the current study, de-individuation and creative thinking (creativity) are connected and the question for further research is, how much can group or social factor affect individual trait of a person.

\section{REFERENCES}

1. Amabile, T. M. (1990) Within You, Without You: The Social Psychology of Creativity, and Beyond. In: M. A. Runco \& R. S. Albert (Eds.) Theories of Creativity. London: Sage, p. 61-91.

2. Barron, F., Harrington, D. M. (1981) Creativity, Intelligence, and Personality. Annual Review of Psychology, 32, p. 439-476.

3. Coleman, L. H., Paternite, C. E., Sherman, R. C. (1999) A Reexamination of Deindividuation in Synchrononous Computer-mediated Communication. Computers in Human Behavior, No 15, p. 5165.

4. Davis, G. A. (1989) Testing for Creative Potential. Contemporary Educational Psychology, No 14, p. 257-274.

5. Diener, E. (1977) Deindividuation: Causes and Consequences. Social Behavior and Personality, No 5(1), p. 143-155.

6. Festinger, L., Pepitone, A., Newcomb, T. (1952) Some Consequences of Deindividuation in a Group. Journal of Abnormal and Social Psychology, No 47, p. 382-389.

7. Guilford, J. Р. (1965) Три стороны интеллекта [Three Sides of Intellect]. А. М. Матюшкин (Ред.), Психология мышления [Psychology of Thinking]. Moscow: Progress, p. 433-456.

8. Heinla, E. (2002) Relation of Child's Creative Thinking to Social and Behavioural Factors. Dissertation. Tallinn: Tallinn University Publishers, $150 \mathrm{p}$.

9. Helson, R. (1999) Personality. In: M. A. Runco \& S. R. Pritzker (Eds.) Encyclopedia of Creativity. Vol. 2, San Diego, CA: Academic Press, p. 361-371.

10. Helson, R., Pals, J. L. (2000) Creative Potential, Creative Achievement, and Personal Growth. Journal of Personality, No 68, p. 1-27.

11. Johnson, R., Downing, L. (1979) Deindividuation and Valence of Cues: Effects on Prosocial and Antisocial behavior. Journal of Personality and Social Psychology, No 37, p. 1532-1538. 
12. Kugihara, N. (2001) Effects of Aggressive Behaviour and Group Size on Collective Escape in an Emergency: A Test between a Social Identity Model and Deindividuation Theory. British Journal of Social Psychology, No 40, p. 575-598.

13. Le Bon, G. (2001) The Crowd: A Study of a Popular Mind. Kitchener, Ontario: Batoche Books (First published 1895), p. 13-45.

14. Lubart, T. I. (1994) Creativity. In: R. J. Sternberg (Eds.) Thinking and problem solving. San Diego, CA: Academic Press, p. 290-332.

15. Maslach, C., Stapp, J., Santee, R. T. (1985) Individuation: Conceptual Analysis and Assessment. Journal of Personality and Social Psychology, No 49, p. 729-738.

16. Postmes, T. (2001) Psychology of Deindividuation. In: P. H. Baltus \& N. H. Smelser (Eds.) The International Encyclopedia of the Social and Behavioral Sciences. Vol. 5, Oxford, England: Pergamom p. 3364-3366.

17. Postmes, T., Spears, R. (1998) Deindividuation and Anti-normative Behavior: A Meta-Analysis. Psychological Bulletin, No 123, p. 238-259.

18. Reicher, S. D. (1984) The St. Paul's 'riot': An Explanation of the Limits of Crowd Action in Terms of a Social Identity Model. European Journal of Social Psychology, No 14, p. 1-21.

19. Reicher, S. D. (1987) Crowd Behaviour as Social Action. In: J. C. Turner, M. A. Hogg, P. J. Oakes, S. D. Reicher, M. S. Wetherell (Eds.) Rediscovering the Social Group: A Self-Categorization Theory. Oxford: Blackwell, p. 171-202.

20. Reicher, S. D., Levine, M. (1994) On the Consequences of Deindividuation Manipulations for Strategic Communication of Self: Identifiability and the Presentation of Social Identity. European Journal of Social Psychology, No 37, p. 15-40.

21. Spielberger, C. D., Sydeman, S. J., Owen, A., Marsh, R. J. (1999) Measuring Anxiety and Anger with State-Trait Anxiety Inventory (STAI) and the State-Trait Anger Expression Inventory (STAXI). In: M. E. Maruish (Eds.), The Use of Psychological Testing for Treatment Planning and Outcomes Assessment, 2nd edition. Mahwah, NJ: Lawrence Erlbaum Associates, p. 993-1021.

22. Starkweather, E. K. (1964) Conformity and Nonconformity as Indicators of Creativity in Preschool Children. Unpublished manuscript. Stillwater, OK: Oklahoma State University.

23. Sternberg, R. J., Lubart, T. I. (1996) Investing in Creativity. American Psychologist, No 51, p. 677688.

24. Torrance, E. P. (1968) Education and Creative Potential. Minneapolis, MN: University of Minnesota Press, $167 \mathrm{p}$.

25. Torrance, E. P. (1974) Torrance Tests of Creative Thinking. Norms and Technical Manual. Bensenville, IL: Scolastic Testing Service, $95 \mathrm{p}$.

26. Van Hook, C. W., Tegano, D. W. (2002) The Relationship between Creativity and Conformity among Preschool Children. Journal of Creative Behavior, No 36(1), p. 1-17.

Mg. Sc. postgraduate in Pedagogics Institute Stanislav Nemeržitski

Lecturer in Department of Applied Creativity, Institute of Arts

Address: Tallinn University, Lai str 13, 10133 Tallinn, Estonia

Phone: +372 53734395

E-mail: stanislav.nemerzitski@ee.redbull.com 